\title{
Linguistic Effects on the Processing of Two-Digit Numbers
}

\author{
Deia Ganayim ${ }^{1,2,3 *}$, Shireen Ganayim¹, Ann Dowker ${ }^{4}$, Sinan Olkun ${ }^{5}$ \\ ${ }^{1}$ The Arab Center for Mind, Brain and Behavior (ACMBB), Sakhnin, Israel \\ ${ }^{2}$ The College of Sakhnin for Teacher Education, Sakhnin, Israel \\ ${ }^{3}$ The Max Stern Yezreel Valley Academic College, Yezreel Valley, Israel \\ ${ }^{4}$ Department of Experimental Psychology, University of Oxford, Oxford, UK \\ ${ }^{5}$ Final International University, Nicosia, Cyprus \\ Email: *info@acmbb.org.il
}

How to cite this paper: Ganayim, D., Ganayim, S., Dowker, A., \& Olkun, S. (2020). Linguistic Effects on the Processing of Two-Digit Numbers. Open Journal of Modern Linguistics, 10, 49-69.

https://doi.org/10.4236/ojml.2020.101004

Received: January 31, 2020

Accepted: February 25, 2020

Published: February 28, 2020

Copyright (c) 2020 by author(s) and Scientific Research Publishing Inc. This work is licensed under the Creative Commons Attribution International License (CC BY 4.0).

http://creativecommons.org/licenses/by/4.0/

(c) (i) Open Access

\begin{abstract}
The syntactic structure of numbers in Arabic mainly differs from that of Hebrew in terms of the order of units and decades. In Arabic (inverted), two-digit numbers are written and read from right to left, i.e. the first digit is the units and the second is the decades ( $24=$ four and twenty), while in Hebrew (non-inverted), the reverse. Therefore, studying transcoding in the two languages may enable us to tease out the relative effects of linguistic experience (first versus second language) and counting system transparency i.e. the syntactic representation of numbers (inverted versus non-inverted number system). For this purpose, the paradigm of reading and writing two-digit numbers from dictation, in both languages was used. Sixty university bilingual students were given two tasks in both Arabic-L1 (First language) and Hebrew-L2 (Second language): One task involved writing two-digit numbers to dictation, and the other involved reading two-digit numbers aloud. Reading times and the error rates were calculated in both languages according to type of error-total errors, substitution errors (replacement of two-digit number units with decades, and vice versa; for example, 23 »32), change errors (change of one digit $23 » 28$ ), and omission errors (omission of one digit; for example $23 » 2$ ). The participants made some errors in reading and especially in writing two-digit numbers. Their commonest errors were substitution errors compared to change and omission errors. Such errors were commoner for numbers which require processing the numerical syntactic structure than for decade numbers, or numbers from 11 to 19 , which require less attention to numerical syntax. Speed and accuracy are greater in Arabic-L1 than Hebrew-L2, although the Arabic counting system has the inversion feature, and is thus less transparent than Hebrew. It is concluded that familiarity with the verbal counting system of the first language has a greater influence
\end{abstract}


on transcoding than the transparency of the counting system. Theoretical and practical implications are discussed.

\section{Keywords}

Two-Digit Numbers, Transcoding, Arabic, Hebrew, Bilinguals

\section{Introduction}

Numbers may be presented differently; for example, Arabic numerals (0123456789)

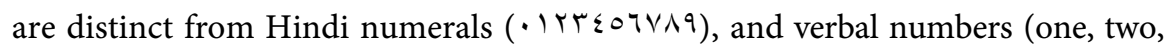
three) and may vary by language. These diverse representations evoke various mental processes that are involved in the understanding, calculation, and production of Arabic numerals and verbal numbers (number words) (Dehaene, 1992).

Naturally, number words are employed mainly in spoken language (as in a conversation) but are often used also when writing small numbers (two oranges, five cars). In contrast, Arabic numerals are used mostly to write multi-digit numbers $(27,564)$ and in mathematical calculations. All educated adults can shift from one notational system (number symbol) to another without substantial difficulty. They can write an Arabic numeral according to dictation or read an Arabic numeral aloud; for example, 4 is equal to ארבע in Hebrew, أربعة in Arabic, and four in English. This step of translating numbers from one context to another is called "transcoding" or "conversion" and is considered a crucial aspect of number processing.

Transcoding is involved in many daily activities, such as telling the time, reading a price, or using telephone numbers, and it is also a prerequisite for calculations. However, transcoding processes are not as easy as they might initially seem to be. The difficulty of transcoding has been studied in children, who require several years of practice to acquire the relevant skills (Brizuela \& Cayton, 2008; Cayton \& Brizuel a, 2007; Noel \& Turconi, 1999; Power \& Dal Martello, 1990; 1997; Scheuer, Sinclair, Merlo de Rivas, \& Tieche-Christinat, 2000; Seron \& Fayol, 1994; Zhou, Wang, Wang, \& Wang, 2006), and well as in adults with dyscalculia caused by brain damage (Deloche \& Seron, 1982a, b; Seron \& Deloche, 984; Seron \& Noel, 1995).

According to the Sapir-Whorf hypothesis (Whorf, 1956) language influences mechanisms of thinking, including mechanisms of number processing (Butterworth, Reeve, Reynolds, \& Lloyd, 2008; De Cruz, 2009). While few nowadays would accept the strong form of the Sapir-Whorf hypothesis, there is evidence for a weak Whorfian effect on numerical abilities. The structure of the verbal counting system has some effect on the number processing and arithmetic. For example, some aspects of number processing appear to be easier in languages such as Chinese, Japanese, Korean and Welsh, which have a transparent counting system, where the decades and units are expressed very explicitly 
(Dowker, Bala, \& Lloyd, 2008; Miura, Kim, Chang, \& Okamoto, 1988) and their acquisition in mathematical operations. Therefore, recent studies on number processing have centered on how and to what degree language affects number processing (Brysbaert, Fias, \& Noel, 1998; Nuerk, Weger, \& Willmes, 2005).

There are many types of numerical systems around the world with different internal structures. They vary in their lexical structure, namely in the system of words used to represent numbers (Arabic: واحد, اثنان, ثنلاثه; Hebrew: אחד, שתיים, שלש; English: one, two, three), as well as in the syntactic structure, i.e. how individual lexical units are composed in order to generate a larger verbal number (Comrie, 2005). In addition to the verbal number systems, there are digit number systems that also vary in their internal structure. They differ in their lexical

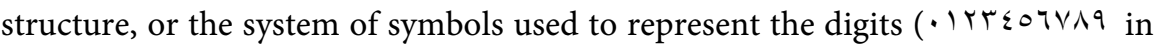
Arabic versus 0123456789 in English and Hebrew), and in their syntactic structure, or the order of units, decades, and hundreds, etc. Thus, the transcoding of numbers from one system (verbal or digits) to another requires control of the coding mechanisms of these verbal and digit systems.

\section{Number order and the inversion feature}

One aspect of counting systems that differs between languages, concerns simple syntax as the order of units and decades. In most languages, the decades precede the units in the verbal counting system, as they do in the so-called Arabic numeral system, as well as the Hindi numeral system which is used by most contemporary Arabic-speakers. In a few languages, the units precede the decade numbers in the verbal counting system (e.g. "two and thirty" for 32). This is usually known as the inversion feature, as the order of decades and units in the verbal counting system is an inversion of their order in the written digit system. Languages that have the inversion feature include German, Dutch and sometimes Czech and Norwegian among European languages, and Arabic among Middle Eastern languages.

Cross-cultural studies of transcoding between number words and numerals have given insights into the influences of the counting system on number processing (Bahnmueller, Moeller, \& Nuerk, 2018; Dowker \& Nuerk, 2016; Göbel, Shaki, \& Fischer, 2011; Seron \& Fayol, 1994).

There have been several studies, mostly with European languages, which indicate that the inversion feature affects some aspects of number processing. Some aspects of number processing, in particular transcoding, have been found to be more difficult in German and Dutch, than in European languages without the inversion feature. German and Dutch participants make more errors, and especially more substitution errors (e.g. writing 43 as 34), when writing digit numbers to dictation than those from other European countries with comparable educational systems but without the inversion feature (Göbel, Moeller, Kaufmann, et al., 2014; Pixner, Moeller, Hermanova, Nuerk, \& Kaufmann, 2011; Zuber, Pixner, Moeller, \& Nuerk, 2009). In the German language, where the unit digit precedes the decade digit, more substitution errors have been found than in 
languages without this characteristic (Zuber et al., 2009; see also Blanken, Dorn, \& Sinn, 1997; Proios, Weniger, \& Willmes, 2002). In a transcoding study in the Czech language, in which numbers can be represented either as "units-decades" or "decades-units," this order of number words affected the number transcoding errors (Pixner, Zuber, Hermanova, Kaufmann, Nuerk, \& Moeller, 2011). These findings clearly indicate that the building linguistic structures, such as the complex structure of two-digit numbers in French or reverse word number order in German, influence number transcoding.

Imbo, Vanden Bulcke, DeBrauwer and Fias (2014) asked child speakers of Dutch (an inverted number language) and French (a non-inverted number language) to write Arabic digits to dictation. Although the number of change errors (e.g., hearing 46 but writing 56) was equal in both groups, the number of substitution errors (e.g., hearing 46 but writing 64) was significantly higher in Dutch-speaking than in French-speaking children. Regression analyses confirmed that language was the only significant predictor of substitution errors.

Most studies have been conducted with children, but similar effects have been found with adults. For example, Lonneman and Yan (2015) found that both German and Chinese participants were slower at addition problems that involved carrying than those that did not, but the effect was significantly greater for the German participants. Brysbaert et al. (1998) found that adult French speakers were better than adult Dutch speakers at reading two-digit numbers aloud, though not at typing the numbers. Thus, the effects of the inversion feature, do not cease to exist even after individuals have become proficient in counting and basic arithmetic, though these effects may be circumscribed: e.g. adults' three-digit number processing does not differ in inverted and non-inverted counting systems (Bahnmueller, Moeller, Mann and Nuerk, 2015).

There have been far fewer studies of number processing in Arabic and other Middle Eastern languages than in European or Pacific Rim languages; but there are some studies which have highlighted the special characteristics of Arabic number processing (Everett, 2005; Ganayim \& Ibrahim, 2014; Ganayim \& Ibrahim, 2015; Nuerk, Weger, \& Willmes, 2005; Prior, Katz, Mahaina, \& Rubinsten, 2015; Shaki, Fisher, \& Petrusic, 2009).

\section{The present study}

The present study deals with bilingual speakers of Arabic, which has the inversion feature, and Hebrew, which does not. It aims to investigate transcoding in the two languages, and to investigate whether performance is influenced by the language being spoken.

The present study investigates the special Arabic numerical system, wherein numbers in general and two-digit numbers in particular differ both lexically and syntactically from the numerical system of the Hebrew language. Arabic is, perhaps ironically, one of the few major modern languages that does not use so-called Arabic numerals, the lexical structure of numbers in Arabic consists of the format $(\cdot 1$ r $纟 07 \vee \wedge 9$ ), while in Hebrew, as in most other languages it has the 
format of (0123456789). The syntactic structure of numbers in Arabic mainly differs from that of Hebrew in terms of the order of units and decades. In Arabic, two-digit numbers are written and read from right to left, i.e. the first digit is the units and the second is the decades ( 24 = four and twenty), while in Hebrew or English, the reading and writing of two-digit numbers occurs from left to right, i.e. the decades digit comes first followed by the units digit $(24=$ twenty-four). Reversing the order of units and decades in Arabic is a basic, inherent feature of two-digit and multi-digit numbers. The contrast between Hebrew and Arabic in this respect is the main focus of the present study.

\section{Objectives and hypotheses}

This study investigates the effect of the syntactic representation of numbers in Arabic on the task of transcoding. For this purpose, it uses the paradigm of reading and writing two-digit numbers from dictation (Brizuela \& Cayton, 2008; Cayton \& Brizuela, 2007; Power \& Dal Martello, 1990; Scheuer, Sinclair, Merlo de Rivas, \& Tieche-Christinat, 2000; Zhou, Wang, Wang, \& Wang, 2006). The participants were bilinguals with Arabic as their first language and Hebrew as a second language. They performed two transcoding tasks, namely reading two-digit numbers and writing two-digit numbers from dictation, in both languages. Reading times and the error rates were calculated in both languages according to type of error-total errors, substitution errors (replacement of two-digit number units with decades, and vice versa; for example, 23 » 32), change errors (change of one digit $23 » 28$ ), and omission errors (omission of one digit; for example 23 »2) If there is an effect of language structure on transcoding, we expect that differences in participants' performance according to the language of the transcoding tasks will be apparent in the reading times and the substitution error rates (e.g. reading or writing 23 as 32 or thirty-two).

The current study examined how the transparency and inversion features of the number system influence the basic mathematical skill of transcoding. It involved the measurement of reading times for two-digit numbers using a stopwatch as well as error rates in writing two-digit numbers in Arabic and Hebrew. We anticipated differences in reading times and error rates between Arabic and Hebrew due to the inversion feature of two-digit numbers in Arabic compared to Hebrew.

Most Arab citizens of Israel speak Arabic as a first language and Hebrew as a second. Therefore, studying their performance in the two languages may enable us to tease out the relative effects of linguistic experience (first versus second language) and counting system transparency (inverted versus non-inverted number system). If linguistic experience is more important, one might expect them to perform better in transcoding tasks in Arabic as their first language; if counting system transparency is more important, one might expect them to perform better in Hebrew, which has a non-inverted counting system.

\section{Method}

Participants: Sixty university students ( 40 male, 20 female) between the ages of 
20 and 35 years $($ Mean $=26.8, S D=5.16)$. All students were bilingual and spoke Arabic as their first language (L1) and Hebrew as a second language (L2). All students were proficient in Arabic as the main teaching language in school and proficient in Hebrew since they learned Hebrew from second grade until university. Although the teaching language of the participants in school years was Arabic, the math text books were in Arabic in elementary school and in Hebrew in junior high school and high school. All the participants were attending a Hebrew-speaking university which had strict Hebrew proficiency requirements for enrolment. According to self-reports, none of them suffered from specific difficulties in mathematics or other academic issues.

\section{Materials and Procedure}

Task: The transcoding tasks in Arabic and Hebrew consisted of two blocks: the writing of digit numbers read by the experimenter and the reading of two-digit numbers aloud (Brizuela \& Cayton, 2008; Cayton \& Brizuela, 2007; Power \& Dal Martello, 1990; Scheuer, Sinclair, Merlo de Rivas, \& Tieche-Christinat, 2000; Zhou, Wang, Wang, \& Wang, 2006). Transcoding in both directions of writing and reading were tested to avoid dependency on the number input format. Each block was composed of 89 transcoding two-digit numbers. To compare the performance of students, numbers ranged from 10 and 100 and included 29 numbers between $10-20$ as well as 29 whole tens (e.g. 60) and 31 remaining two-digit numbers. The order in which numbers were presented was random and different for each student.

Procedure: The experimenter tested each student individually in a quiet room. Students and the experimenter were seated at a table so that students could not read the comments that were written about their performance. Students did not receive any feedback about their answers. They could request a short break during the test if they desired one, but they could not do so during the number reading task since the reading time was measured.

For the transcoding tasks, students were asked to write digit numbers from dictation and to read numbers in Hebrew and Arabic. In the number writing from dictation task, students were prompted to write numbers from dictation on a blank sheet of white paper (A4). The experimenter dictated one two-digit number at a time to the students. If necessary or the student did not hear the number, the experimenter dictated the number again.

In the number reading task, students received a list of two-digit numbers. In each block, the experimenter initially provided two examples for students as an introduction to the task. During the number reading task, the experimenter measured the time with a stopwatch. The number reading task and number writing from dictation task were performed alternately in Arabic and Hebrew.

\section{Results}

\section{Number reading task}

The average reading time in seconds for the number list was calculated for 
each language. A paired t-test of the significant main effe average reading times in Arabic and Hebrew was performed. A ct of language was observed ( $\mathrm{t}$ [58] = 3.9, $p<0.0001, \mathrm{~d}=0.675$ ), and reading times for numbers in Arabic (Mean = $84.25, \mathrm{SD}=36.1)$ were lower than reading times in Hebrew (Mean $=110.37$, SD $=41.16$ ).

The error rates were calculated in both languages according to type of error-total errors, substitution errors (replacement of two-digit number units with decades, and vice versa; for example, $23 » 32$ ), change errors (change of one digit 23 " 28), and omission errors (omission of one digit; for example 23 " 2)-as a function of the three number categories - two-digit numbers between 11 and 19 (e.g. 11, 12, 13), two-digit numbers of whole tens (e.g. 20, 30, 40), and the remaining two-digit numbers (e.g. 43, 62). A repeated measures analysis of variance (RM-ANOVA) of the error rates was conducted with the language, error types, and number categories as within-subject variables.

No significant main effect of the language was observed $(F[1,58]=0.26$, MSE $=0.045, p=0.61$ ). Thus, the error rates in Arabic (Mean: 2.54\%, SD: $1.2 \%$ ) were similar to those in Hebrew (Mean: 3.22\%, SD: 1.1\%).

A significant main effect of the number category was observed $(\mathrm{F}[2,116]=$ 16.96, MSE $=2.715, p<0.0001, \eta^{2}=0.752$ ). In a post-hoc analysis of paired comparisons of error rate differences, the error rates of students in the remaining two-digit number category (e.g. 43, 62) were higher than those in the number category of 11 to 19 and whole tens (e.g. 20, 30, 40) that were similar (see Figure 1).

Significant main effect of the error type was observed $(\mathrm{F}[3,174)=14.67$, MSE $\left.=0.763, p<0.0001, \eta^{2}=0.705\right)$. In a post-hoc analysis of paired comparisons of error rate differences, the error rates of substitution exceeded those of change errors and omission errors, which were lower and similar (see Figure 2).

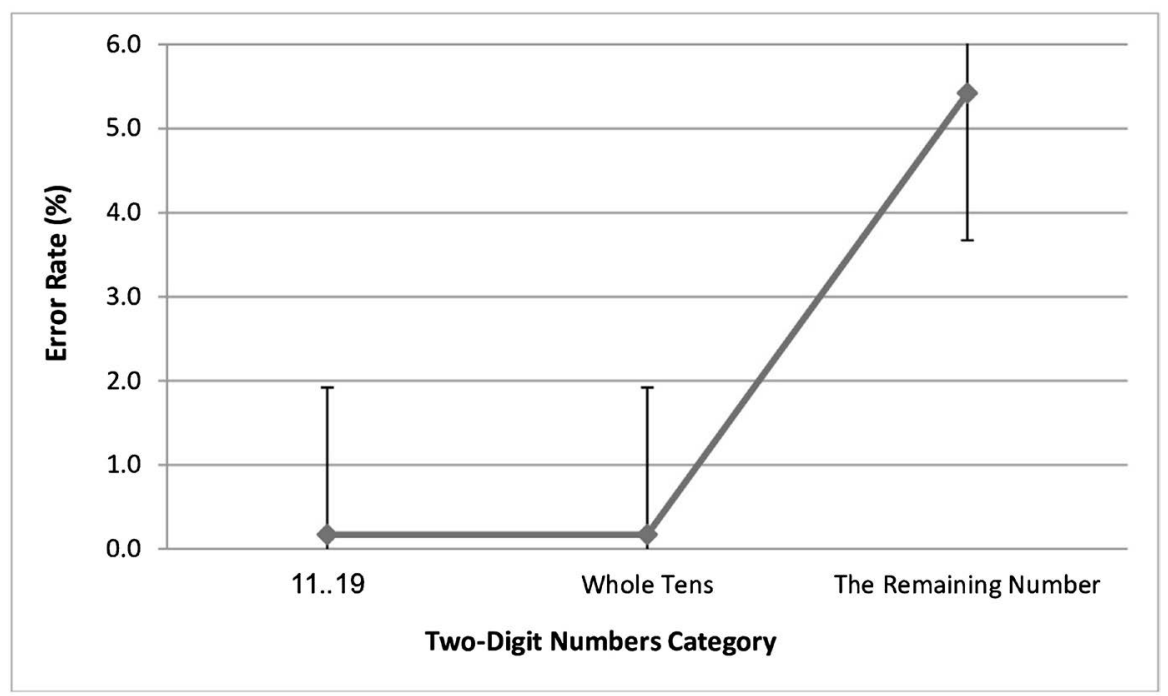

Figure 1. The error rates are a function of two-digit numbers categories (11-19, whole tens, the remaining numbers). 


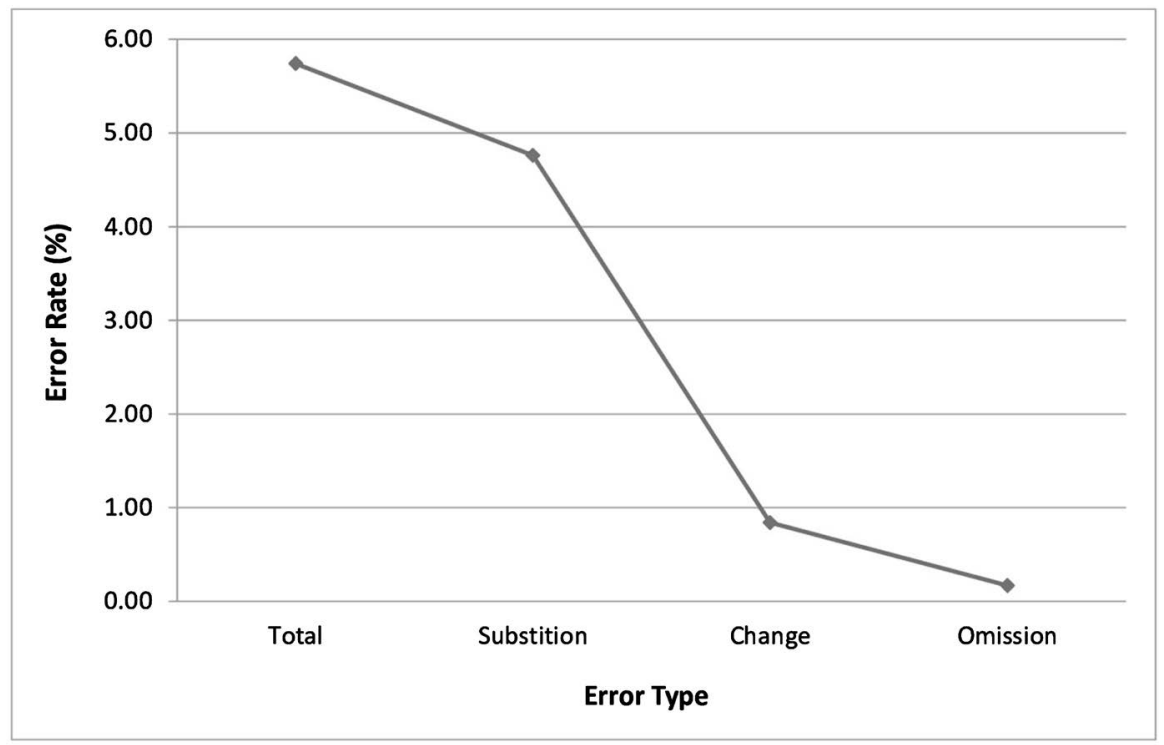

Figure 2. Error rates are a function of error type (total, substitution, change, omision).

No interaction was observed between the language (Arabic, Hebrew) and the number category (11-19, whole tens, the remaining numbers) $(F[2,116]=0.31$, MSE $=0.054, p=0.73$ ).

No interaction was observed between the language (Arabic, Hebrew) and the error type (total, substitution, change, omission $)(\mathrm{F}[3,174]=0.59, \mathrm{MSE}=0.36$, $p=0.623)$.

A significant interaction between the number category (11-19, whole tens, the remaining numbers) and the error type (total, substitution, change, omission) was observed $\left(\mathrm{F}[6,348]=14.4, \mathrm{MSE}=0.751, p<0.0001, \eta^{2}=0.699\right)$. In a post-hoc analysis of paired comparisons of differences in error rates, there was no difference in the error rates of omission according to the number category. Change error rates were lower for two-digit numbers of whole tens and 11 to 19 but were significantly higher for the remaining numbers category. The error rates of substitution were lower and similar for two-digit numbers of whole tens and two-digit numbers from 11 to 19 but were significantly higher for the remaining two-digit numbers category (see Figure 3).

No significant three-way interaction between the language (Arabic, Hebrew), the number category (11-19, whole tens, the remaining numbers), and the error type (total, substitution, change, omission) was observed $(\mathrm{F}[6,348]=0.68$, MSE $=0.041, p=0.663$ ).

\section{Results of number writing from dictation task}

The error rates were calculated for both languages (Arabic, Hebrew) for type of error-total errors, substitution errors (replacement of two-digit number units with decades, and vice versa; for example, $23 » 32$ ), change errors (change of one digit $23 » 28$ ), and omission errors (omission of one digit, for example 23 »2)-as a function of the three number categories-two-digit numbers between 11 and 19 (e.g. 11, 12, 13), two-digit numbers of whole tens (e.g. 20, 30, 40), and 


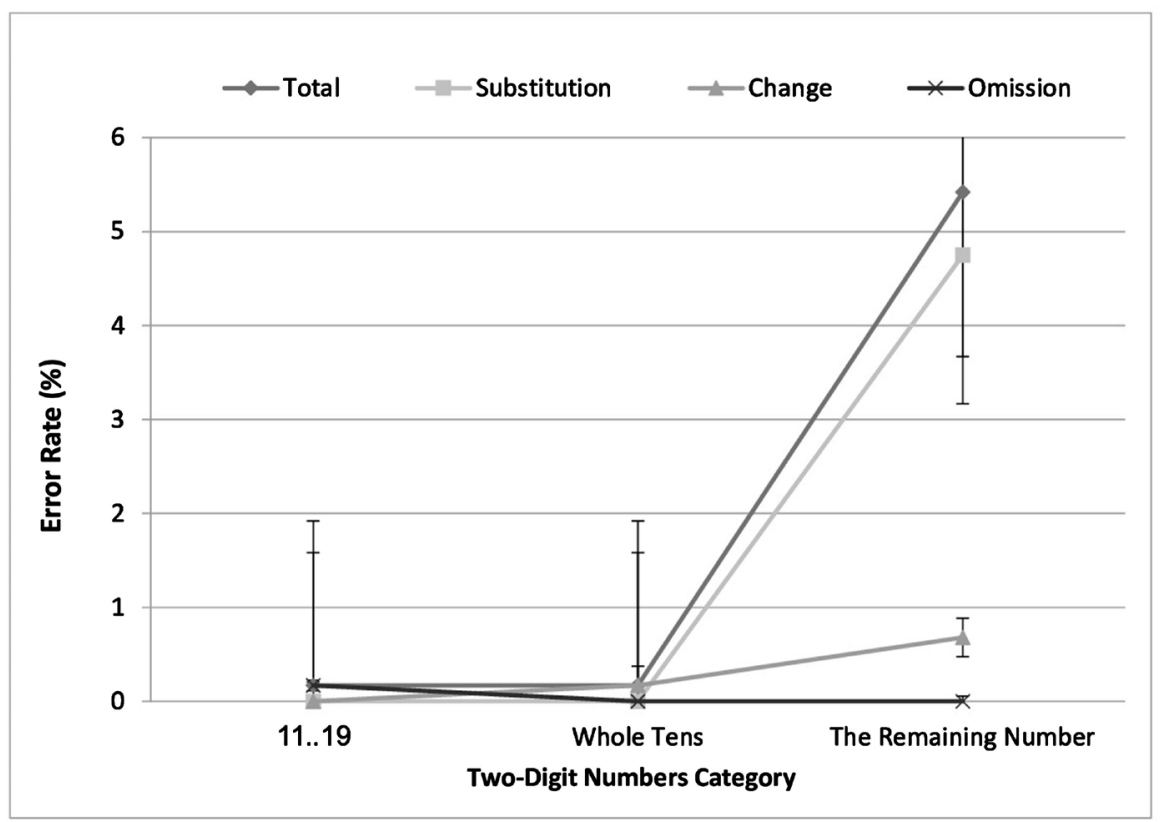

Figure 3. Presents the error rates according to the number category (11-19, whole tens, the remaining numbers) and the error type (total, subsitution, change, omission).

the remaining two-digit numbers (for example, 43 and 62). An RM-ANOVA of the error rates was performed with the language, error type, and number category as within-subject variables.

A significant main effect of language was observed $(\mathrm{F}[1,58]=6.68, \mathrm{MSE}=$ $\left.0.723, p<0.05, \eta^{2}=0.476\right)$, and error rates for two-digit number writing from dictation were lower in Arabic (Mean $=0.4 \%, \mathrm{SD}=1.3 \%$ ) than in Hebrew (Mean $=3.54 \%, \mathrm{SD}=1.4 \%)$.

A significant main effect of the number category was observed $(\mathrm{F}[2,116]=$ 3.96 , MSE $\left.=0.511, p<0.05, \eta^{2}=0.366\right)$. In a post-hoc analysis of paired comparisons of error rate differences, the error rates of students in the remaining two-digit numbers category (e.g. 43, 62) and in the number category of 11 to 19 were similar and higher than in whole tens (e.g. 20, 30, 40) that were similar (see Figure 4).

A significant main effect of error type was observed $(\mathrm{F}[3,174]=9.42, \mathrm{MSE}=$ $\left.0.45, p<0.0001, \eta^{2}=0.565\right)$. In a post-hoc analysis of paired comparisons of error rate differences, the error rates of substitution were higher than change errors and omission errors, which were lower and similar (see Figure 5).

No interaction was observed between the language (Arabic, Hebrew) and the number category $(11-19$, whole tens, the remaining numbers $)(\mathrm{F}[2,116]=1.63$, MSE $=0.274, p=0.2$.

A significant interaction was observed between the language (Arabic, Hebrew) and the error type (total, substitution, change, omission) $(\mathrm{F}[3,174]=3.42$, MSE $\left.=0.13, p<0.05, \eta^{2}=0.34\right)$. In a post-hoc analysis of paired comparisons of error rate differences, a significant difference in substitution error was observed between Arabic and Hebrew. Substitution error rates in two-digit number writing 


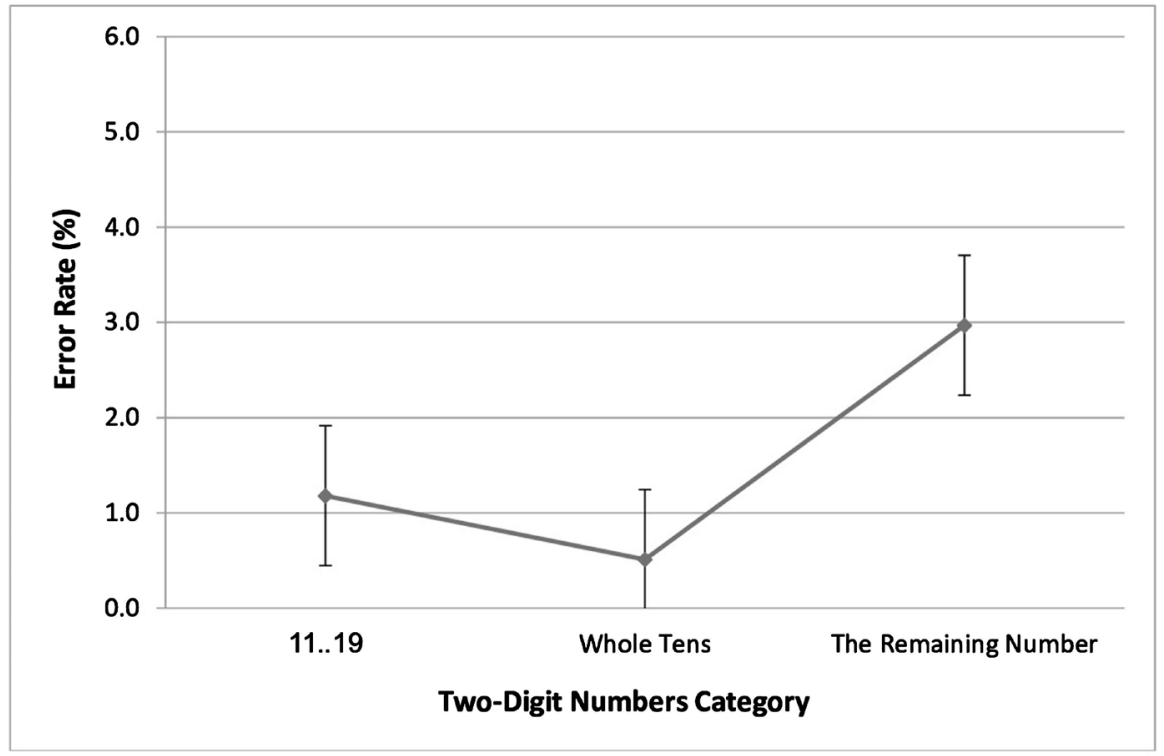

Figure 4. The error rates are a function of the two-digit number category (11-19, whole tens, the remaining numbers).

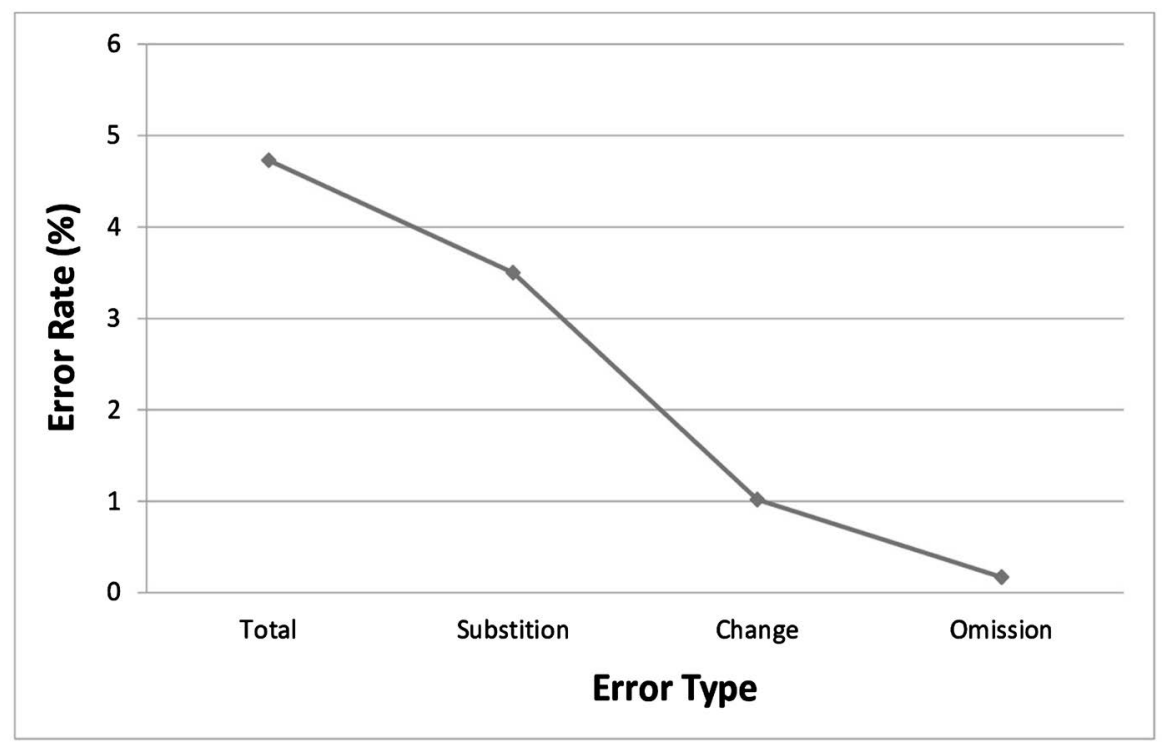

Figure 5. Error rates are a fuction of the error type (total, substitution, change, omission).

from dictation were higher in Hebrew than in Arabic. However, no differences were observed in change error rates and omission error rates between Arabic and Hebrew (see Figure 6).

A significant interaction was observed between the number category (11-19, whole tens, the remaining numbers) and the error type (total, substitution, change, omission $\left(\mathrm{F}[6,348]=6.83, \mathrm{MSE}=0.269, p<0.0001, \eta^{2}=0.481\right)$. In a post-hoc analysis of paired comparisons of differences in error rates, there was no difference in the error rates of omission according to the number category. Additionally, the change error rates were lower for two-digit numbers of whole tens and 11 to 19 but were significantly higher for the remaining numbers cate- 
gory. The error rates of substitution were lower and similar for two-digit numbers of whole tens and two-digit numbers from 11 to 19 but were significantly higher for the remaining two-digit number category (see Figure 7).

A significant three-way interaction was observed between the language (Arabic, Hebrew), the number category (11-19, whole tens, the remaining numbers), and the error type (total, substitution, change, omission) $(\mathrm{F}[6,348]=$ $2.15, \operatorname{MSE}=0.107, p<0.05, \eta^{2}=0.27$ ). In a post-hoc analysis of paired comparisons of error rate differences in Arabic, there was no difference in the various types of error rates (total, substitution, change, omission) according to the number category (11-19, whole tens, the remaining numbers). In addition, in a post-hoc analysis of paired comparisons of differences in error rates in Hebrew, there was no difference in the change and omission types of error rates according to the number category, although the error rates of substitution were lower

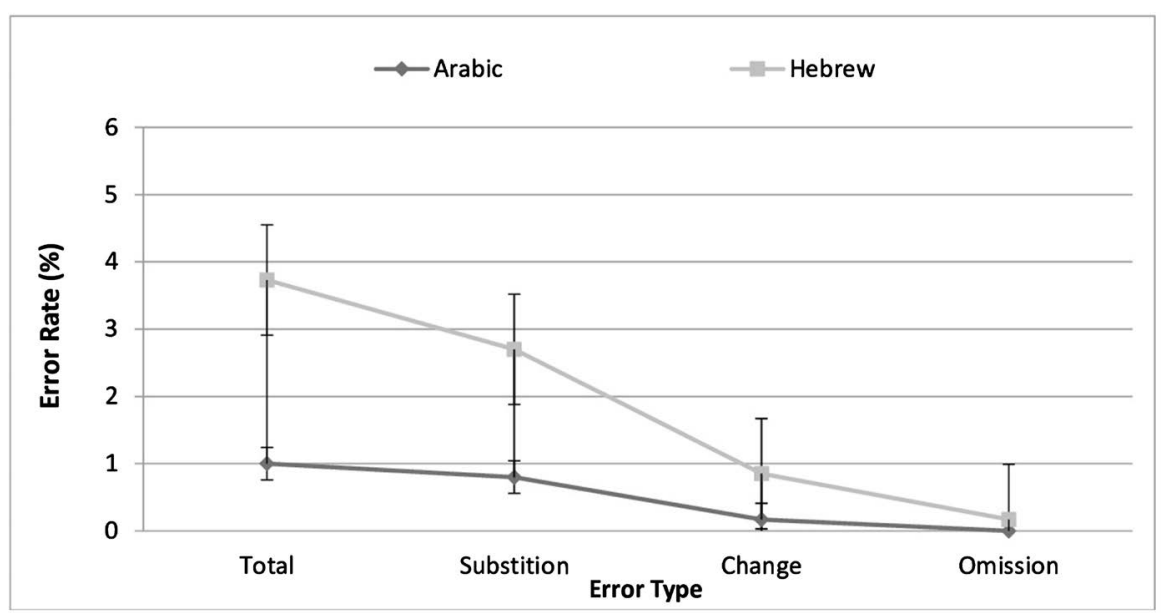

Figure 6. Indicates the error rates according to the language (Arabic, Hebrew) and the error type (total, subsitution, change, omission).

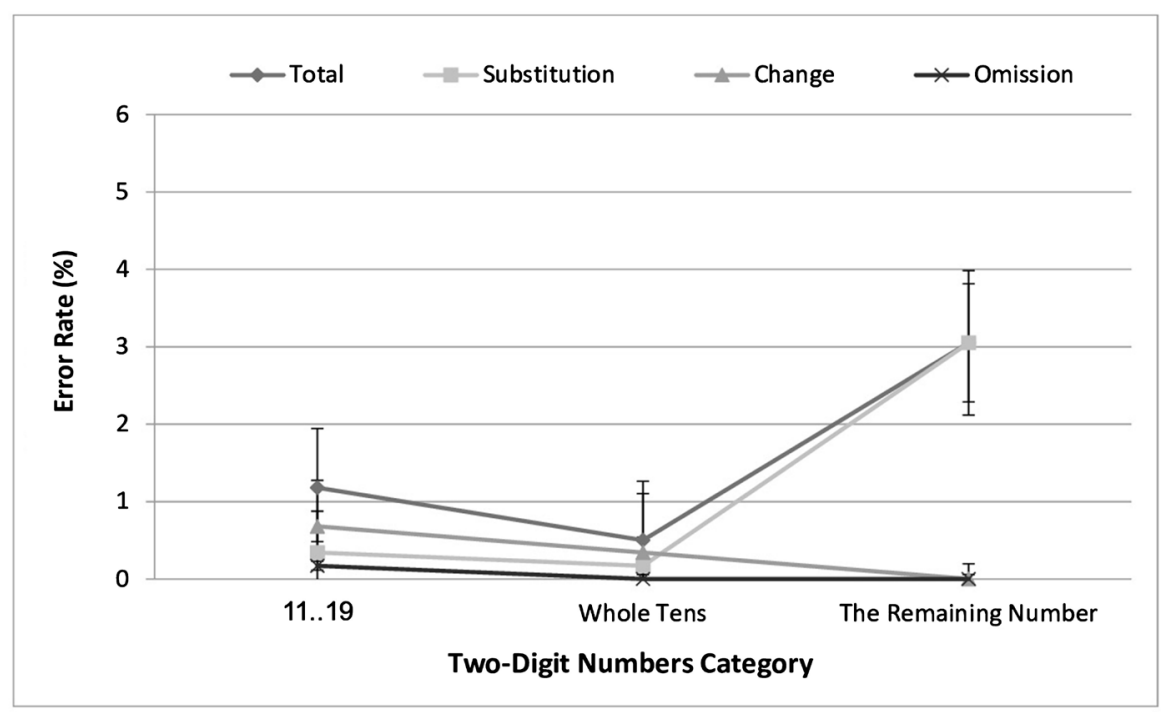

Figure 7. Illustrates the error rates according to the number category (11-19, whole tens, the remaining numbers) and the error type (total, substitution, change, omission). 
and similar in two-digit numbers of whole tens and two-digit numbers from 11 to 19 and were significantly higher in the remaining two-digit number category (see Figure 8, Figure 9).

To identify any differences in error rates according to language (Arabic, Hebrew) between the two-digit number reading task and the two-digit number writing from dictation task, a mixed RM ANOVA of the error rates was performed. Transcoding tasks were the between-subject variable, and the languages were the within-subject variable.

No significant main effect of the transcoding task was observed $(\mathrm{F}[1,58]=$ $0.356, \mathrm{MSE}=0.356, p=0.553$ ). Thus, the error rates in the number reading task

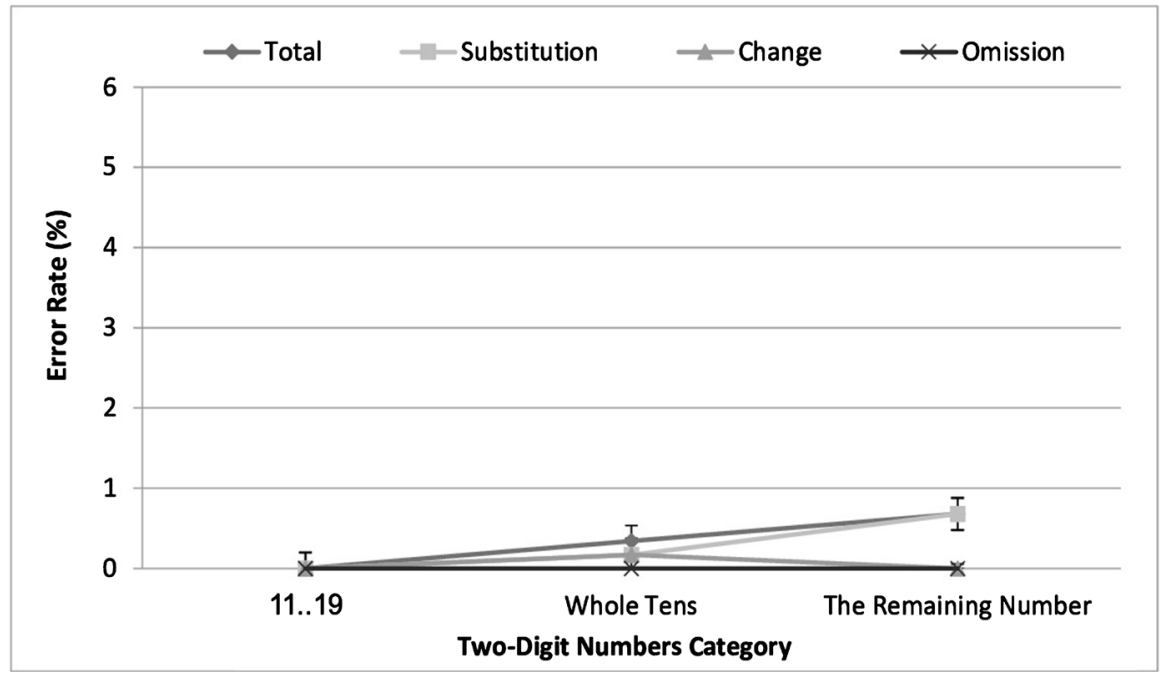

Figure 8. Displys the error rates in Arabic according to the number category (11-19, whole tens, the remaining numbers) and the error type (total, substution, change, omission).

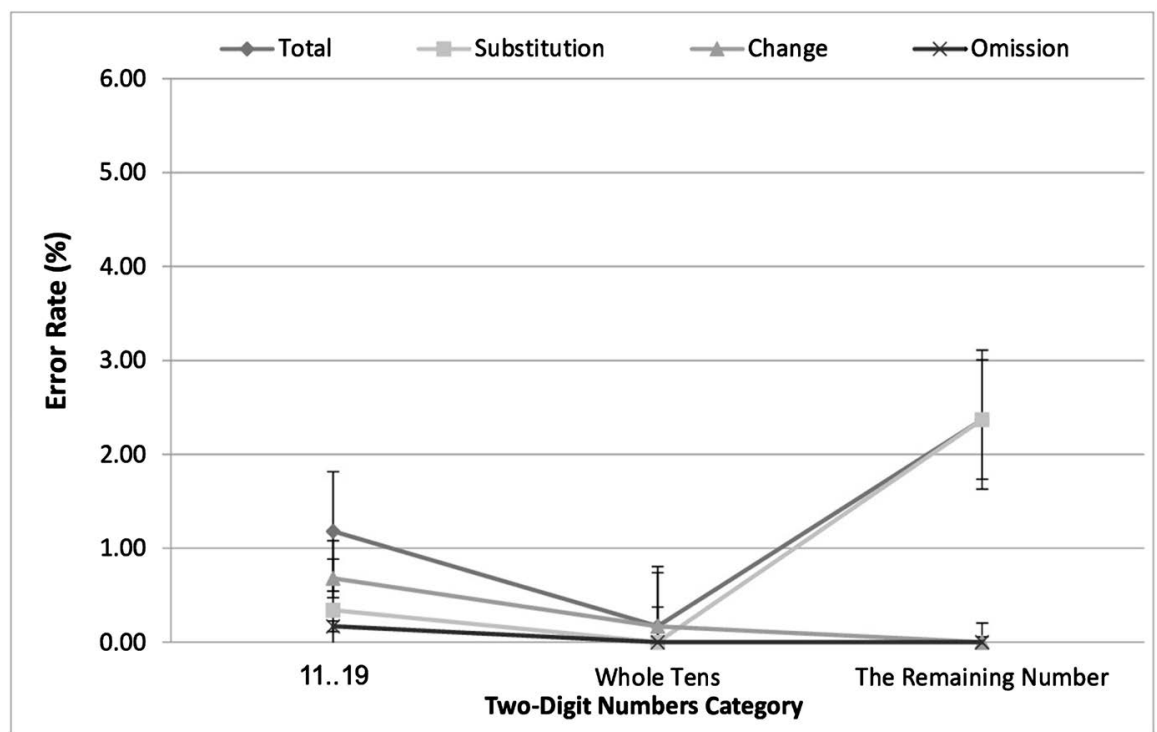

Figure 9. Indicates the error rates in Hebrew according to the number category (11-19, whole tens, the remaining numbers) and the error type (total, substution, change, omission). 
(Mean: $5.74 \%$, SD: $1.38 \%$ ) were similar to those in the number writing from dictation task (Mean: $4.73 \%$, SD: $1.15 \%$ ). In addition, no significant main effect of the language was observed $(\mathrm{F}[1,58]=3.473, \mathrm{MSE}=3.473, p=0.067)$, although there was a tendency toward significance, and the error rates in Arabic (Mean: 3.54\%, SD: $1.03 \%$ ) were similar to those in Hebrew (Mean: 6.932\%, SD: 1.5\%).

Finally, no interaction was evident between the transcoding task (number reading, number writing from dictation) and the language (Arabic, Hebrew) (F $[1,58]=1.736, \mathrm{MSE}=1.736, \mathrm{p}=0.193)$.

\section{Discussion}

The current research findings suggest that the first language (L1) of bilinguals has a stronger influence on two-digit number reading compared to the second language (L2), as the reading times of two-digit numbers in Arabic (L1) were shorter than those in Hebrew (L2). The error rates in writing two-digit numbers from dictation in Arabic were lower than those in Hebrew. Substitution error rates were higher in Hebrew.

However, many aspects of two-digit number reading were similar in the two languages. Error rates were similar in the two languages, and so were the relative frequencies of the different types of error. In both languages, substitution errors were more frequent than change and omission errors. There were also similar number type effects in both languages, error rates were lower for the 11-19 numbers and the decade numbers than for the remaining two-digit numbers, for which syntactic structure was more central. There was no interaction between the effects of number type and of language. In Arabic (L1), there were no differences in types of error rates (total, substitution, change, omission) according to the number category (11-19, decade numbers, the remaining numbers). In Hebrew (L2), there were no differences in the change and omission types of error rates according to the number category. However, the substitution error rates were lower and in 11-19 numbers and decade numbers than in the remaining numbers.

Thus, the language of dictation affects adult bilinguals in the process of transcoding two-digit numbers from dictation. This effect is particularly evident for error rates (or accuracy), which were lower in the first language (Arabic) than in the second language (Hebrew). Moreover, the language of two-digit numbers differentially affected the error types (total, substitution, change, omission) according to the number category (11-19, whole tens, the remaining numbers). The results suggest that the different syntactic structure of two-digit numbers (order of units and decades) of the numerical system and the inversion feature in particular in the first language (Arabic-L1: units-decades) compared to the second language (Hebrew-L2: decades-units) significantly affects the transcoding process in writing two-digit numbers from dictation.

Error rates of change (e.g. representing 32 as thirty-five or fifty-two instead of thirty-two) in two-digit number transcoding in reading and writing from dicta- 
tion were low as previously found even with children. Seron, Deloche and Noel (1991) found that French- and Belgian-speaking children rarely evidenced lexical difficulties at a younger age in incorrect use or selection of word numbers or digits to represent numbers (e.g. using the word "five" to represent four, or vice versa) (Seron, Deloche, \& Noel, 1991). The adults in this study made very few such errors, and, no logogram errors (e.g. writing thirty-two as 203) at all.

The low error rates of omission (e.g. representing thirty-two as three or two) in transcoding two-digit numbers in reading and writing from dictation indicate that some adult bilinguals also ignored several digits when they were not able to read the two-digit numbers, which reinforces the earlier findings concerning of similar errors of this type among Italian children (Power \& Dal Martello, 1997).

There is remarkable similarity between the performance of Arabic-speaking adults and German speakers compared to French speakers The type of errors appears to reflect the inversion feature that complicates the writing of two-digit numbers from dictation, as substitution error rates were high and predominated over other error types (Zuber et al., 2009; see also Blanken et al., 1997; Proios et al, 2002). Since participants were proficient in Arabic as their first language (L1) and Hebrew as a second language (L2) (learned Hebrew from second grade until university), no significant difference was found in error rates between Arabic and Hebrew in the reading two-digit numbers task.

The present study suggest that error rates are higher for numbers with a more complex units and decades structure, that requires more working memory capacity. This complexity is more pronounced in two-digit numbers, where processing depends on the numerical syntactic structure than in numbers that depend less on a numerical syntactic structure (numbers 19-11) or those that lack such a structure (decade numbers. These differences are particularly marked with regard to substitution error rates. This pattern was found in both Hebrew and Arabic, but somewhat more so in Hebrew. Performance was somewhat worse in Hebrew, the participants' second language, even though Hebrew is non-inverted.

Thus, the participants' familiarity with the language seemed to be a greater influence on their performance than the correspondence within the language between the oral counting system and the written number system. Although the Hebrew counting system is more transparent than the Arabic counting system, as it does not have the inversion feature, the tasks were still somewhat more difficult for the participants in Hebrew than in Arabic. It should be noted that all the participants were attending a Hebrew-speaking university, where they were studying, reading and speaking in Hebrew much of the time; and which had strict Hebrew proficiency requirements for enrolment. Admittedly, we do not have information as to the Hebrew proficiency level of individuals, and it would be desirable to include this factor in future studies. Nevertheless, we can assume that all participants had a high level of proficiency in their second language. Despite this, and despite the fact that the tasks involved only transcoding and not calculation, the language had a significant effect on performance. 
Some researchers have argued that bilinguals and multi-linguals prefer to use their first language to perform mental calculations because of the rapid coding in their first language (Dewaele, 2007; McClain \& Shin Huang, 1982), which could explain the difference in reading times of two-digit numbers in favor of the first language (Arabic-L1) over the second language (Hebrew-L2) and the lower error rates in Arabic-L1 compared to in Hebrew-L2 in the two-digit number writing from dictation task. This finding resembles that of a previous study, which concluded that bilinguals performed mathematical calculations more quickly and accurately when calculations were presented in their first language (L1) compared to in their second language (L2) (Frenck-Mestre \& Vaid, 1993; Ganayim \& Ibrahim, 2014; Ganayim \& Ibrahim, 2015). It is also notable that in the current study, the number reading skills of participants in their second language (Hebrew-L2) were better than their writing skills.

These effects were only on the syntactic aspects of transcoding, not the lexical aspects, where performance in both languages was near-perfect. Thus, the participants' performance indicates that they had highly effective control on the number lexicons in both their first and their second language, but that they had imperfect command of numerical syntax, as reflected in the frequency systematic substitution errors in transcoding in general and in two-digit number writing from dictation in particular. This was especially true in the second language and was most marked for those two-digit numbers that relied the most on numerical syntactic structure. This is consistent with the participants' near-perfect lexical performance and weaker syntactic performance; with the participants' greater difficulty with numbers that required more syntactic processing and were less likely to remembered as strings; and with their better performance on tasks in the first language, where there was presumably greater practice in childhood.

These findings may have some parallels with those of Booth, Clenton and Van Herwegen (2018), with regard to word order processing in a second language. Booth et al. (2018) gave syntactic and semantic tasks involving English word strings to individuals who were learning English as a second language. One group came from Italic Indo-European language first language backgrounds (French, Spanish, Portuguese, Italian and Romanian) whose default word order is subject-verb-object, as is the case for English. The other group's first language was Japanese, whose default word order is subject-object-verb. The Japanese participants were slower than the Indo-European first-language participants for both syntactic and semantic judgements and made more errors for semantic but not syntactic tasks. This suggests that people are poorer at even quite simple judgements in a second language, and that differences in typical word order between the first and second language may increase the difficulty. One important difference, however, is that syntactic effects were less strong than semantic effects in Booth et al.'s (2018) word order study, while syntactic effects were the main ones observed in the current, number order study.

As we only studied Arabic-Hebrew bilinguals, it is difficult to tell whether the 
participants had greater difficulty with syntactic processing in their second - and possibly even their first-language, because of having to deal with languages with contrasting number order systems, resulting in mutual interference; or whether syntactic processing would create similar difficulty in other bilinguals or even monolinguals. Future studies should investigate whether individuals would have similar difficulties with syntactic processing of two-digit numbers in a second language, even if it followed the same number order as the first language. It is also important to study monolingual Hebrew and Arabic participants, to investigate the relative role of specific language effects and the effects of using a first versus second language. The results of the present study suggest that the latter are more important, but a study including monolinguals would be necessary to confirm this.

It is also desirable to look at order effects in calculation as well as in transcoding.

In a previous study Ganayim \& Ibrahim (2014) assessed the effect of language lexical-syntactic structure and magnitude semantic access on numerical processing de by contrasting the performance of Arabic/Hebrew bilinguals in a digital (Hindi-digits/Arabic-digits) and verbal numerical comparison task (Arabic, an inverted language: Units-Decades, Hebrew, a non-inverted language: Decades-Units). They found in the digital presentation format (Experiment 1) a regular distance effect in Arabic language-Hindi digits and Hebrew language-Arabic digits, characterized by an inverse relation between reaction times and numerical distance with no difference in the mean reaction times of participants in Arabic-L1 and Hebrew-L2. This indicated that both lexical digits of two-digit numbers in L1 and L2 are similarly processed and semantically accessed. However, in the verbal presentation format (Experiment 2) a similar pattern of distance effect was found, but the mean reaction times in Arabic were lower than in Hebrew in each numerical distance. This indicated that the processing of two-digit number words in L1 and L2 is semantically accessed and determined by the syntactic structure of each language.

The same was found in another study by Ganayim \& Ibrahim (2014) who assessed the effect of presentation language and format on the compatibility effect of two-digit numbers by contrasting performance of Arabic/Hebrew bilinguals in a digital (Hindi digits/Arabic digits) and verbal numerical comparison task. They found in digital presentation format a regular compatibility effect in Hindi digits and Arabic digits characterized by lower reaction-time (RT) means for compatible number pairs than incompatible ones with no difference in the RT means of participants in the two languages, Arabic language-Hindi digits as a mother tongue and Hebrew language: Arabic digits as a second language. However, in verbal presentation format, different patterns of compatibility effect were found in Arabic and Hebrew verbal numbers. In Arabic number words, a regular compatibility effect was found, while in Hebrew number words, no compatibility effect was found. This reflected the influence and modulation of the lexical-syntactic structure of the language in two-digit numbers comparison. 
Evidently, these differences in the compatibility effect advocated and strengthened the claim that two-digit numbers comparison is influenced by the number's presentation format. Different modes of presentation of two-digit numbers (digital vs. verbal) can lead to different number comparison styles.

There is one study of a similar participant group, that suggests that compatibility between the language structure in arithmetical statements and in number names can influence performance. Prior et al. (2015) asked Arabic-Hebrew bilinguals to verify whether arithmetical statements were true or false. Participants carried out the task faster and more accurately for problems where the language structure corresponded to the structure of the arithmetical statement. For example, in Arabic, "Five plus twenty equals five and twenty" and " $5+20=25$ " were easier to verify than "twenty plus five equals twenty five" or " $20+5=25$ ", while the reverse was true in Hebrew. This is presumably because the former was more compatible with number names of the form "five and twenty" and the latter with number names of the form "twenty-five". It would be interesting to give participants both the arithmetical statement verification task and the transcoding tasks, and to examine relationships between the tasks in the first and second language.

There is another factor that may have influenced the results. So far, we have mostly assumed that the inversion feature simply makes the Arabic number system less transparent than the Hebrew number system, in the same way that the German number system is less transparent than the English number system. But there is another characteristic of the languages, which might work in the opposite direction. Both Hebrew and Arabic, unlike European languages, are written from right to left. This means that in Arabic, the order of numbers in the verbal counting system corresponds to the direction of reading and writing, whereas in Hebrew it does not. Shaki et al. (2009) has suggested that this compatibility between the direction of writing and the order of numbers in the counting system may make the Arabic number system easier in some ways than the Hebrew number system. Future studies should directly compare transcoding in Arabic and Hebrew with transcoding in inverted and non-inverted European languages, to gain a greater understanding of the possible effects of such compatibility differences.

Apart from the specific findings, the present study confirms the view that cross-linguistic studies of basic mathematical skills can be of great theoretical and practical implementations this should be extended in future studies, both of transcoding and of other basic skills.

From a practical standpoint, teaching mathematics programs in general, screening procedures of mathematical difficulties and diagnostic testing of dyscalculia, intervention programs and treatment plans of mathematical disabilities and dyscalculia in special should take into account these findings. The present data suggest that teaching mathematics and math textbooks in first language-L1 (as Arabic in the current study) is preferable than second language-L2 (as Hebrew in the current study) since accuracy and speed of math performance in the 
first language is expected to be better even for adult bilinguals. The initial stage of teaching transcoding should begin with the numbers 11 to 19 and decade numbers eliciting less errors moving into the remaining two-digit numbers since these numbers require processing the numerical syntactic structure than for decade numbers, or numbers from 11 to 19 , which require less attention to numerical syntax. In math difficulties screening and diagnosis, error analysis of transcoding performance may be indicative of the level of the math difficulty. Omission and change errors in transcoding two-digit numbers are less frequent and may indicate basic level of math difficulty in the numerical lexicon while substitution errors may indicate such a difficulty in the numerical syntactic structure.

One potential limitation of the present study is that reaction time was measured with stopwatches. In future studies, computerized measures of reaction time should be used, to gain greater precision, and to provide finer-grained comparisons of speed.

\section{Author Contributions}

D.G, S.G, A.D and S.O contributed equally to the design and implementation of the research, to the analysis of the results and to the writing of the manuscript.

\section{Acknowledgements}

This work was carried out under the supervision of Prof. Yohanan Eshel and Dr. Daniel Fitousi, as partial fulfilment of the requirements of a master's degree at the Department of Psychology, The University of Haifa. I would especially like to thank my supervisors, whose insights and guidance continually challenged me throughout this experience. I wish to thank them for all the time and effort they invested in me and for all the freedom they gave me to pursue my ideas throughout this gratifying process.

\section{Funding}

No funding was provided for this study.

\section{Ethics Statement}

The study "Linguistic effects on two-digit numbers processing" was carried out in accordance with the recommendations of the ethics committee for human research, the faculty of social sciences, the University of Haifa. The protocol was approved by the ethics committee for human research, the faculty of social sciences, the University of Haifa. All subjects gave written informed consent in accordance with the Declaration of Helsinki.

\section{Conflicts of Interest}

The authors declare no conflicts of interest regarding the publication of this paper. 


\section{References}

Bahnmueller, K., Nuerk, H. C., \& Moeller, K. (2018). A Taxonomy Proposal for Types of Interactions of Language and Place-Value Processing in Multi-Digit Numbers. Frontiers in Psychology, 9, 1024. https://doi.org/10.3389/fpsyg.2018.01024

Blanken, G., Dorn, M., \& Sinn, H. (1997). Inversion Errors in Arabic Number Reading: Is There a Nonsemantic Route? Brain and Cognition, 34, 404-423. https://doi.org/10.1006/brcg.1997.0917

Booth, P., Clenton, J., \& Van Herwegen, J. (2018). L1-L2 Semantic and Syntactic Processing: The Influence of Language Proximity. System, 78, 54-64. https://doi.org/10.1016/j.system.2018.07.011

Brizuela, B. M., \& Cayton, G. A. (2008). Interpretation and Production of Numbers in 5-7 Year Old Children through Different Representational Systems: Factorial Analyses. In 4th International Conference on Writing, Speech, and Context. Queretaro, Mexico.

Brysbaert, M., Fias, W., \& Noel, M. P. (1998). The Whorfian Hypothesis and Numerical Cognition: Is "Twenty-Four" Processed in the Same Way as "Four-and-Twenty"? Cognition, 66, 51-77. https://doi.org/10.1016/S0010-0277(98)00006-7

Butterworth, B., Reeve, R., Reynolds, F., \& Lloyd, D. (2008). Numerical Thought with and without Words: Evidence from Indigenous Australian Children. Proceedings of the National Academy of Sciences of the USA, 105, 13179-13184.

https://doi.org/10.1073/pnas.0806045105

Cayton, G. A., \& Brizuela, B. M. (2007). First Graders' Strategies for Numerical Notation, Number Reading and the Number Concept. In J.-H. Woo, H.-C. Lew, K.-S. Park, \& D.-Y. Seo (Eds.), Proceedings of the 31rst Annual Meeting of the International Group for the Psychology of Mathematics Education (Vol. 2, pp. 81-88). Seoul: Seoul National University.

De Cruz, H. (2009). Is Linguistic Determinism an Empirically Testable Hypothesis? Logique \& Analyse, 208, 327-341.

Dehaene, S. (1992). Varieties of Numerical Abilities. Cognition, 44, 1-42. https://doi.org/10.1016/0010-0277(92)90049-N

Dewaele, J. M. (2007). Predicting Language Learners' Grades in the L1, L2, L3 and L4: The Effect of Some Psychological and Sociocognitive Variables. International Journal of Multilingualism, 4, 169-197. https://doi.org/10.2167/ijm080.0

Dowker, A., \& Nuerk, H.-C. (2016). Linguistic Influences on Mathematics. Frontiers in Psychology, 7, 1035. https://doi.org/10.3389/fpsyg.2016.01035

Dowker, A., Bala, S., \& Lloyd, D. (2008). Linguistic Influences on Mathematical Development: How Important Is the Transparency of the Counting System. Philosophical Psychology, 21, 523-538. https://doi.org/10.1080/09515080802285511

Everett, C. (2005). Independent Cross-Cultural Data Reveal Linguistic Effects on Basic Numerical Cognition. Language and Cognition, 5, 99-104.

https://doi.org/10.1515/langcog-2013-0005

Frenck-Mestre, C., \& Vaid, J. (1993). Activation of Number Facts in Bilinguals. Memory and Cognition, 21, 809-818. https://doi.org/10.3758/BF03202748

Ganayim, D., \& Ibrahim, R. (2014). Number Processing of Arabic and Hebrew Bilinguals: Evidence Supporting the Distance Effect. Japanese Psychological Research, 56, 153-167. https://doi.org/10.1111/jpr.12035

Ganayim, D., \& Ibrahim, R. (2015) Number Processing in Arabic and Hebrew Bilinguals: Evidence Supporting the Compatibility Effect. Journal of Cross-Cultural Psychology, 46, 565-578. https://doi.org/10.1177/0022022115573316 
Göbel, S. M., Moeller, K., Kaufmann, L., Pixner, S., \& Nuerk, H.-C. (2014). Language Affects Symbolic Arithmetic in Children: The Case of Number Word Inversion. Journal of Experimental Child Psychology, 119, 17-25. https://doi.org/10.1016/j.jecp.2013.10.001

Göbel, S. M., Shaki, S., \& Fischer, M. H. (2011). The Cultural Number Line: A Review of Cultural and Linguistic Influences on the Development of Number Processing. Journal of Cross-Cultural Psychology, 42, 543-565. https://doi.org/10.1177/0022022111406251

Imbo, I., Vanden Bulcke, C., De Brauwer, J., \& Fias, W. (2014). Sixty-Four or Four-and-Sixty? The Influence of Language and Working Memory on Children's Number Transcoding. Frontiers in Psychology, 5, 1-10. https://doi.org/10.3389/fpsyg.2014.00313

Lonneman, J., \& Yan, S. (2015). Does Number Word Inversion Affect Arithmetic Processes in Adults? Trends in Neuroscience and Education, 4, 1-5. https://doi.org/10.1016/j.tine.2015.01.002

McClain, L., \& Shih Huang, J. Y. (1982). Speed of Simple Arithmetic in Bilinguals. Memory and Cognition, 10, 591-596. https://doi.org/10.3758/BF03202441

Miura, I. T., Kim, C. C., Chang, C. M., \& Okamoto, Y. (1988). Effects of Language Characteristics on Children's Cognitive Representation of Numbers: Cross-National Comparisons. Child Development, 59, 1445-1450. https://doi.org/10.2307/1130659

Noel, M. P., \& Turconi, E. (1999). Assessing Number Transcoding in Children. European Review of Applied Psychology, 49, 295-302.

Nuerk, H.-C., Weger, U., \& Willmes, K. (2005). Language Effects in Magnitude Comparison: Small, But Not Irrelevant. Brain and Language, 92, 262-277.

https://doi.org/10.1016/j.bandl.2004.06.107

Pixner, S., Moeller, K., Hermanova, V., Nuerk, H. C., \& Kaufmann, L. (2011). Whorf Reloaded: Language Effects on Non-Verbal Number Processing in 1st Grade-A Trilingual Study. Journal of Experimental Child Psychology, 108, 371-382. https://doi.org/10.1016/j.jecp.2010.09.002

Pixner, S., Zuber, J., Hermanova, V., Kaufmann, L., Nuerck, H.-C., \& Moeller, K. (2011). One Language Two Number-Word Systems and Many Problems: Numerical Cognition in the Czech Language. Research in Developmental Disabilities, 32, 2683-2689. https://doi.org/10.1016/j.ridd.2011.06.004

Power, R. J. D., \& Dal Martello, M. F. (1990). The Dictation of Italian Numerals. Language and Cognitive Processes, 5, 237-254. https://doi.org/10.1080/01690969008402106

Power, R. J. D., \& Dal Martello, M. F. (1997). From 834 to Eighty Thirty-Four: The Reading of Arabic Numerals by Seven-Year-Old Children. Mathematical Cognition, 3, 63-85. https://doi.org/10.1080/135467997387489

Prior, A., Katz, M., Mahajna, I., \& Rubinsten, O. (2015). Number Word Structure in First and Second Language Influences Arithmetic Skills. Frontiers in Psychology, 6, 266. https://doi.org/10.3389/fpsyg.2015.00266

Proios, H., Weniger, D., \& Willmes, K. (2002). Number Representation Deficit: A Bilingual Case of Failure to Access Written Verbal Numeral Representations. Aeuropsychologia, 40, 2341-2349. https://doi.org/10.1016/S0028-3932(02)00085-4

Scheuer, N., Sinclair, A., Merlo de Rivas, S., \& Tieche-Christinat, C. (2000). When a Hundred and Seventy One Is Written 10071: Five to Eight-Year-Olds' Production of Written Numerals. Infancia y Aprendizaje, 90, 31-50. https://doi.org/10.1174/021037000760087955

Seron, X., \& Fayol, M. (1994). Number Transcoding by Children: A Functional Analysis. 
British Journal of Developmental Psychology, 12, 281-300. https://doi.org/10.1111/j.2044-835X.1994.tb00635.x

Seron, X., Deloche, G., \& Noel, M. P. (1991). Number Transcoding by Children: Writing Arabic Numbers under Dictation. In J. Bideaud, C. Meljac, \& J. P. Fisher (Eds.), Pathway to Number (pp. 245-264). Hillsdale, NJ: Erlbaum.

Shaki, S., Fischer, M. H., \& Petrusic, W. M. (2009). Reading Habits for Both Words and Numbers Contribute to the SNARC Effect. Psychonomic Bulletin and Review, 16, 328-331. https://doi.org/10.3758/PBR.16.2.328

Whorf, B. L. (1956). Language, Thought and Reality. Cambridge, MA: MIT Press.

Zhou, X., Wang, Y., Wang, L., \& Wang, B. (2006). Kindergarten Children's Representation and Understanding of Written Number Symbols. Early Childhood Development and Care, 176, 33-45. https://doi.org/10.1080/0300443042000302645

Zuber, J., Pixner, S., Moeller, K., \& Nuerk, H.-C. (2009). On the Language-Specificity of Basic Number Processing: Transcoding in a Language with Inversion and Its Relation to Working Memory Capacity. Journal of Experimental Child Psychology, 102, 60-77. https://doi.org/10.1016/j.jecp.2008.04.003 